\title{
Real World Connections in High School Mathematics Curriculum and Teaching ${ }^{1}$
}

\author{
Gökhan Karakoç ${ }^{2}$ and Cengiz Alacacı ${ }^{3}$
}

\begin{abstract}
Making real world connections in mathematics curricula and in teaching mathematics is generally viewed favorably within the educational community, however, little empirical research has examined how and why to use real world connections in mathematics education based on the views of experts. This study describes the feasibility of the use of real world connections according to high school mathematics teachers and academicians of mathematics education. Opinions of high school mathematics teachers $(n=16)$ and academicians $(n=8)$ about advantages, disadvantages, and examples of real world connections are elicited and reported. Teachers and academicians report several advantages of the use of real world connections in teaching mathematics as well as its disadvantages and limitations. Suggestions about dealing with limiting factors for using real world connections are also reported.
\end{abstract}

Keywords: Mathematics curriculum, real world connections, mathematics teaching

DOI: $10.16949 /$ turcomat.76099

\section{Introduction}

Recognizing and applying mathematics outside of the field of mathematics is an important goal of instructional programs for students at all levels across national curricula (e.g., MoNE, 2012; NCTM, 2000). This study is an attempt to gather and report the views of experienced mathematics teachers and mathematics education academicians regarding the use of real world connections in high school mathematics. Real world connections is used as a general term for the multitude of connections, including "simple analogies, word problems, analysis of real data, discussion of mathematics in society, hands-on representations of mathematics concepts, and mathematical modelling of real phenomena" (Gainsburg, 2008, p.200). Designs of curricula in different countries with specific reference to the use of real world connections, place of the connections in assessment strategies, the relationship between the use of real world connections and affective domain of mathematics teaching are discussed below in the light of related literature.

\subsection{Real world connections in the design of high school mathematics curriculum}

Ability to relate mathematics to real life is a common goal of school mathematics curricula in many countries. (e.g., Department of Education, 2013; MoNE, 2012; NCTM, 2000). According to official Turkish curriculum guidelines for high schools, "development of students' mathematical process skills and the use of these skills in solving real life problems" are two general goals of teaching mathematics (MoNE, 2012, p. 4-5). Purposes of a mathematics curriculum are intimately connected to the world we are living in. People

\footnotetext{
${ }^{1}$ This paper is based on a master's thesis entitled "Real World Connections in High School Mathematics Curriculum and Teaching" by the first author in Curriculum and Instruction Program at Bilkent University, Ankara Turkey, which was completed in May 2012 .

${ }^{2}$ Mathematics Teacher, Bilkent Erzurum Laboratory School, gkarakoc@bilkent.edu.tr

${ }^{3}$ Prof. Dr., Istanbul Medeniyet University, Faculty of Educational Sciences, alacaci65@gmail.com
} 
ought to learn mathematics for understanding the world around us, solving problems of employment and their daily lives (Blum, 2002; Cuban, 1976; Özdemir \& Üzel, 2011; Patton, 1997). In fact, we know after a well-known study on Brazilian candy-sellers, that even a child with minimal schooling, through every day activities and real or realistic contexts, such as selling candy, can use sophisticated reasoning in mathematical tasks. However, these children could not perform at the same level when they were asked to do equivalent arithmetical operations with paper and pencil (Saxe, 1988).

In England, the newly revised national curriculum effective in 2014 identifies problem solving as one of the main aims of the mathematics curriculum. The national curriculum specifies "modelling situations mathematically" and "interpreting and solving problems including financial contexts" as targets of instruction. These aims have close connotations to real world connections (Department of Education, 2013). In the United States, recognition and application of mathematics in contexts outside of mathematics is a major purpose of school mathematics according to the National Council of Teachers of Mathematics. Connections is one of the ten curriculum standards of the National Council of Teachers of Mathematics in the US. The standard refers to three different types of connections; connections of a mathematical concept to other mathematical concepts, to a field of science or to the real world (NCTM, 2000).

One theoretical approach that deserves mention is Realistic Mathematics Education, as it makes using real world connections in school mathematics its main premise. Realistic Mathematics Education insists upon using realistic contexts in school mathematics at all times. Mathematization of reality is the key term in this approach. Hans Freudenthal of the Netherlands, who developed this approach, argues that learning mathematics should always start with and stay within reality (Gravemeijer, \& Terwel, 2000). Principles of realistic mathematics education are as follows: "(1) Developing instruction based in experientially real contexts... (3) Designing opportunities to build connections between content strands, through solving problems that reflect these interconnections.... (5) Designing activities to promote pedagogical strategies that support students' collective investigation of reality" (Hirsch, 2007, p.81- 82). Even though realistic mathematics education is related to making real world connections conceptually, the two terms are not exactly synonymous. Making real world connections refers to a variety of issues that can be decided upon at different levels and educational contexts; the term "realistic mathematics education" on the other hand communicates a well-defined stance with strong implications for the use of realistic contexts in mathematics education. In fact, this study will provide an opportunity -albeit indirectly, to see how teachers and academicians view the main thesis of the realistic mathematics education approach, starting and staying with realistic contexts in mathematics instruction at all times.

There is a perception that assessment practices in mathematics education are often not in line with the educational reform movements in many countries. For example, the gap between the intended and the attained curriculum may be due to students' lack of 
experience in practical mathematics tasks similar to the ones used in Trends in International Mathematics and Science Study (TIMSS) performance assessment items (Vos \& Kupier, 2005).

Similarly, in PISA (Programme for International Student Assessment), "an individual's capacity to identify and understand the role that mathematics plays in the world, to make well-founded judgments and to engage in mathematics, in ways that meet the needs of that individual's life as a constructive, concerned, and reflective citizen" is being assessed (Blum, 2002; p.151). One possible reason for the under-achievement of Turkish students in international assessment tests like PISA may be their lack of familiarity with the items used in these tests and the mismatch between the contexts that are used in school based assessments and contexts used in international test items.

\subsection{Affective goals of mathematics}

Affective factors have an important role on students' learning (Reyes, 1984). Students' conceptions about the nature of mathematics, perceived usefulness and difficulty of mathematics, are related to the affective domain. Students' attitudes about whether they like or dislike mathematics or their motivation to study mathematics may influence their performance. Among the suggestions to motivate students are to bring flexibility to lessons, and to use contexts that arouse students interests (Sorensen, 2006).

In fact, real world connections in mathematics are often cited as a way to raise the motivation of students. Additionally, it can bring benefits such as facilitating better understanding of mathematical concepts, motivating students, and improving students' attitudes towards mathematics (Gainsburg, 2008).

The abstract nature of mathematics is one of the reasons that may lead students into thinking that mathematics is difficult. Using real world connections in mathematics lesson is one way to tackle this problem, as Muijs and Reynolds (2011) explain:

A model that has been proposed is one in which the teacher starts off what a realistic example or situation turns into a mathematical model, leading to mathematical solutions which are then reinterpreted as a realistic solution. This strategy would certainly be useful in linking mathematical and real world knowledge and applications. (p. 261)

Some educators, on the other hand, suggest that starting with real world connections and eliciting abstract information from a given problem may not always produce desirable results. There might be difficulties and even some disadvantages of using these connections in classroom instruction (Anderson, Reder \& Simon, 2000; Boaler, 2002).

\subsection{Possible problems with using real world connections}

There are studies that looked into the issue of mathematics taught in real world contexts for students from various backgrounds (e.g., Lubienski, 1998). Lubienski's findings showed that students who come from higher socio-economic backgrounds were more comfortable in solving problems situated in a real world context. They were able to make generalizations and relate to the intended mathematical ideas. On the other hand, students 
from lower socio-economic backgrounds focused on real world constraints in the problems and sometimes missed the mathematical ideas involved. She concluded that although problems in real world contexts could help some students and serve as powerful motivators, students who were from lower socio-economic backgrounds could have a more difficult time in learning mathematics in context.

Another concern about "bringing some realism" to mathematics education by including real world contexts in the curriculum is related to the meaningfulness of these contexts for students (Boaler, 2002). If students were unfamiliar with the context, doing mathematics in these contexts for students was not straight forward. Students' familiarity with these contexts and areas of their interest should be considered while using these connections. Effective use of real world connections requires using examples which are connected to pupils' actual experience (Muijs \& Reynolds, 2011), a premise similar to the main thesis of the Realistic Mathematics Education (Heuvel-Panhuizen, 2003).

Using real world contexts may not always have a positive effect on students' performance due to the extra time it takes and limited generalizability for the taught procedures in this approach (De Bock, Verschaffel, Janssens, Van Dooren \& Claes, 2003). Another possible problem is related to teachers' level of comfort in using these connections and how the teachers are prepared, since most of in service teachers are used to teaching mathematics in traditional ways starting with the abstract (Wubbels, Korthagen \& Broekman, 1997). Wubbels and his colleagues (1997) recommended that prospective teachers should be prepared to see the possibilities and potentialities of using real world connections in teaching mathematics by having a firsthand experience of learning (perhaps re-learning) mathematics in the new way.

In summary, even though the potential of using real world connections is widely seen in a favorable light in curriculum documents, among educators and in many studies, there are indicators of potential problems as well. Teachers who live through the realities of classroom instruction on a day to day basis and teacher educators in universities are familiar with this instructional and curricular issue based on their experience. There is, however, little or no empirical study in Turkey that collects and compiles the views of high school mathematics teachers and mathematics education academicians. The purpose of this study is to collect, analyze and report the opinions of high school mathematics teachers and mathematics education academicians on the feasibility, advantages, disadvantages and limitations of the use of real world connections as well as the examples and ways of using real world connections in mathematics curriculum and in teaching. Results of this study can inform curriculum designers, teachers, teacher educators and policy makers on this important issue of high school mathematics.

The study sought to answer the following questions.

1. What do high school teachers and academicians think about the advantages, disadvantages and limitations of using real world connections in high school 
mathematics curricula and in teaching mathematics? Based on their views, what might be ways of resolving or dealing with these limitations and disadvantages?

2. What do high school mathematics teachers and mathematics educators think about how real world connections are used effectively for learning and teaching mathematics?

3. What do high school mathematics teachers and academicians think about the feasibility of real world connections and the ways of using them in high school mathematics curricula and teaching mathematics in Turkish classrooms?

4. What examples of the use of real world connections in mathematics curricula do high school mathematics teachers and academicians suggest in high school mathematics topics?

The term feasibility in the third research question referred to the considerations of participants with regard to the use of real world connections within given classroom environments, and in relation to academic levels of students, Turkish university entrance exams and preparedness of Turkish high school mathematics teachers.

\section{Methodology}

\subsection{Research design}

Data was collected using the Delphi method from the teachers and academicians in this study (Joiner \& Landreth, 2005). This method was used as it allows collecting data from a relatively larger group of subjects without requiring face to face interaction compared to, for example, interview method. The method also provides a structured way of reaching a consensus about issues and questions from a group of participants (Wiersma \& Jurs, 2009).

The study was conducted with the participation of two groups of experts -eight academicians and sixteen high school mathematics teachers. Participation was sought on a voluntary basis and solicited via e-mail sent to a larger group of teachers and academicians. Positive responses were received from about half of the original group of teachers and academicians to whom the solicitation e-mail was sent. Academicians with doctoral degrees in mathematics education whose tenure ranged from instructors to associate professor ( 2 associate professors 4 assistant professors, 2 instructors) were from two state universities in Ankara, Turkey. Teachers with more than five years of teaching experience were selected from two private high schools, again in Ankara. Even though conditions of private schools may somewhat differ from state schools, similarities may outweigh the dissimilarities as both types of schools use the same national curriculum. It was thought that issues about the place of real world connections in mathematics curricula and teaching will be elicited from a more complete perspective with the participation of both teachers with their practical experience and academicians with their general knowledge of the curriculum.

\subsection{Data collection and analysis}

The first round of the study was conducted with seven open-ended questions. The questions were developed to elicit the main issues as viewed by teachers and academicians associated with the use of real world connections in high school mathematics from various perspectives based on our readings from literature and our own knowledge about Turkish high schools. They addressed advantages, disadvantages, limitations of using real world 
connections in mathematics, examples of real world connections for high school mathematics topics, possible places of real world connections in mathematics lessons, appropriateness of real world connections to the classroom environment and the level of students, the use of real world connections in university entrance exams in Turkey, the preparedness of Turkish high school mathematics teachers in using real world connections, and participants' suggestions for its effective use. The questions are given in Appendix A. These questions were administered by using an online form. The link for the form was sent with an e-mail to the participants. Participants were able to write in their answers in their own words in the online form.

Responses to the questions were compiled and analyzed qualitatively to draw out repeating ideas from the responses. Analysis of the answers to the questions revealed 6 distinct ideas or themes for advantages, 6 for disadvantages, 4 for limitations, 3 for possible places of real world connections, 4 for customization of real world connections to students' levels and to classroom environment, 3 for appropriateness of real world connections to the university entrance exams, 5 for preparedness of the high school teachers for using real world connections, totaling 31 altogether. An inter-rater reliability test (by going through all the answers and doing a spate coding) was performed on half of the data by a mathematics teacher educator (an academician) to ensure that there was agreement on the themes extracted from the qualitative data. An agreement of more than $95 \%$ was achieved between the two coders, and disagreements were resolved.

Of the 31 items, a list of which is given below, items from 1 to 16 are related to the first research question (advantages, disadvantages, and limitations question), items from 17 to 19 are related to the second research question (the question about effective use of real world connections) and items from 20 to 31 to the third research question (the feasibility question). Additionally, examples of real world connections given by the participants for the topics of high school mathematics, which was about the fourth research question, are elicited directly from the first round questionnaire, and this question was not part of data collection in the second round.

The 31 themes were converted into statements followed by a Likert scale to elicit the level of agreement from participants. The questionnaire comprised of these statements was used as the data collection tool for the second round. Three options were given in the Likert scale ('agree', 'disagree', and 'no opinion'). Therefore, in the second round, the same group of participants who participated in the first round indicated their agreement or disagreement on each item, unless they had no opinion about the question. The 31 items in relation to the seven open-ended questions of the first round are listed below.

The first set of 6 items concerned the advantages of the real world connections:

1. Increases motivation and interest in mathematics,

2. Helps to improve conceptual, meaningful and permanent learning, 
3. Helps the development of students' mathematical process skills (reasoning, communication, problem-solving, and analytical thinking),

4. Helps students develop consciousness about their future career choices by showing occupational fields in which mathematics is used,

5. Helps students develop a positive attitude towards mathematics,

6. Facilitates generalization and abstraction of mathematical ideas and concepts.

The second set of items concerned the disadvantages and limitations of using real world connections:

7. There is no significant disadvantage,

8. It may result in misconceptions (e.g. the concept of similarity carries different meanings in mathematics and the real world),

9. Makes abstract thinking difficult, some topics should remain abstract,

10. If given examples are complex, to learn the mathematics of the problem can be difficult,

11. Benefits of the lessons might be limited to the given real world problem and it might be difficult to transfer acquired knowledge to other situations,

12. Students may think that mathematics is only limited to real life,

13. It is not suitable to use real world connections for each topic in a high school mathematics curriculum,

14. The heavy content of the curriculum and lack of time may make it difficult to use connections,

15. Lack of adequately equipped teachers and their reluctance is a kind of limitation,

16. It is a limitation, if given examples are unrealistic and not related to students' experiences.

The third set of items addressed the actual examples of real world connections for the topics of the Turkish high school mathematics curriculum. These are presented in a separate section below.

The fourth set of items concerned the possible places of real world connections in mathematics lessons provided by the following items:

17. Real world connections should be taught before abstract generalizations,

18. This situation is not generalizable, possible places of these connections depends on the topic and nature of the problems,

19. If problems are application oriented, it is more useful to use them towards the end of the lessons.

The fifth set of items concerned the customization of the connections to students' level and to classroom environment:

20. Using these connections is suitable for any student group and is always effective,

21. More suitable for groups of students who have lack of interest towards mathematics,

22. Problems shouldn't be complicated in less able student groups, 
23. There is no need to use the connections for very able student groups.

The sixth set of items was about the appropriateness of real world connections to the university entrance exams:

24. Real world connected problems should be included in the university entrance exams,

25. There should be practical examples of the university entrance exams after using these connections in lessons,

26. There might be a lack of time in the exams to solve these problems.

Finally, the seventh set of items addressed the preparedness of the teachers to use real world connections:

27. Most high school teachers are not able to use these connections,

28. There should be elective courses in education faculties to teach student teachers how to use these connections effectively,

29. Using real world connections and mathematical modelling should be included in in-service teacher training,

30. There should be studies to develop sources of real world problems,

31. Real world connected examples should be included in the curriculum to improve the awareness of teachers.

Responses to the second round of 31 items in the Likert scale were analyzed quantitatively. Percentages of 'agreement', 'disagreement', and 'no opinion' were computed for each item across participants as a way of seeking consensus among the participants.

\section{Results}

Results from the second round questionnaire in the Likert scale and examples of real world connections for each topic in the high school mathematics curriculum are reported in this section. Firstly, levels of consensus on the advantages, disadvantages and limitations of using real world connections in a high school mathematics curriculum and in classroom teaching are as follows:

\subsection{Advantages of using real world connections in a high school mathematics curriculum}

The overwhelming majority of the participants agreed that making real world connections in mathematics helps improve or develop students':

- Motivation and interest in mathematics (96\%)

- Positive attitudes towards mathematics (92\%)

- Mathematical process skills such as reasoning and problem-solving (96\%)

- Conceptual and permanent learning (100\%) 
- Awareness of the choice of future careers $(88 \%)$

- Ability to generalize mathematical ideas $(75 \%)$

\subsection{Disadvantages of using real world connections in high school mathematics}

The majority of the participants agreed that if real world examples are complex, to learn the mathematics from these problems can be difficult (63\%). Slightly less than half of the participants disagreed that when real world connections are used in mathematics, the gains of the lessons might be limited to the given real world problem and it might be difficult to transfer the new knowledge to other situations (46\%). Fewer participants agreed with this statement $(42 \%)$.

Three quarters of the participants disagreed that using real world connections makes students think that mathematics is only limited to real life (75\%) and may result in misconceptions (e.g., the concept of similarity carries different meanings in mathematics and real sense) $(71 \%)$. The majority of the participants disagreed that using real world connections makes abstract thinking difficult and some topics should remain abstract $(58 \%)$. Finally, two thirds of the participants agreed that there was no significant disadvantage of using real world connections in mathematics $(66 \%)$.

\subsection{Limitations of using real world connections in mathematics}

The majority of the participants agreed that the heavy content of the curriculum and lack of time is a kind of limitation in using real world connections (58\%), and an overwhelming majority agreed that the lack of adequately equipped teachers and their reluctance was another limitation (92\%). The great majority of the participants agreed that it was a limitation, if given examples are unrealistic and not related to students' experiences $(66 \%)$, and it is not suitable to use real world connections for each topic in the high school mathematics curriculum $(71 \%)$.

\subsection{Possible places of real world connections in mathematics lessons}

About half of the participants agreed that real world connections should be used before abstract generalizations (46\%); however, they agreed that if problems are application oriented, it is also useful to teach them towards the end of the lessons (54\%). On the other hand, the great majority of the participants agreed that this situation is not generalizable, possible places of these connections depend on the topic and nature of the problems (71\%).

\subsection{Appropriateness of using real world connections to students' levels and classroom environment}

Slightly more than half of the participants agreed that using these connections is suitable for any student group and is always effective (54\%), and over three quarters of them think that problems shouldn't be complicated for less able students (79\%). On the other hand, three quarters of the participants disagreed that using these connections is more suitable for groups of students who lack interest towards mathematics $(75 \%)$, and they also disagreed with the statement that there is no need to use these connections for very able students $(75 \%)$. 


\subsection{Appropriateness of real world problems to the university entrance exams}

The great majority of participants agreed that real world connected problems should be included in the university entrance exams (63\%) and, after using these connections, practical examples similar to the university entrance exam questions should be given in lessons (71\%). Slightly less than half of the participants disagreed that there might be a lack of time in the exam to solve these problems (46\%), but over one third of the participants agreed with this statement (38\%).

\subsection{Preparedness of the high school teachers to use real world connections}

A great majority of participants thought that most high school teachers are not equipped to use real world connections in instruction (88\%). For solutions to the problem, an overwhelming majority of the participants agreed that:

- There should be elective courses in education faculties to teach student teachers how to use the real world connections effectively ( $92 \%$ ),

- Using real world connections and mathematical modelling should be included in in-service teacher training (96\%),

- There should be studies to develop sources of real world problems (96\%),

- Examples of real world connections should be included more in the curriculum than it is now to improve the awareness of teachers $(96 \%)$.

\subsection{Results of the real world connections examples suggested by the experts}

Table 1 shows the most relevant items of the examples for real world connections for the topics of a high school mathematics curriculum, offered most frequently by the participants. For some topics, two different examples were suggested by equal numbers of participants; in this case both were included.

Table 1. The most germane items of real world connections examples suggested for each topic

\begin{tabular}{ll}
\hline Logic & Computer software, algorithms and electrical circuits: $\mathrm{n}=10$ \\
\hline $\begin{array}{l}\text { Relations, functions, and } \\
\text { operations }\end{array}$ & Machines, input/output and factory/product relations: $\mathrm{n}=6$ \\
\hline Sets & $\begin{array}{l}\text { Classification of distinct objects which have common } \\
\text { properties: } \mathrm{n}=10\end{array}$ \\
\hline Numbers & $\begin{array}{l}\text { Calculations in shopping, bank accounts and grades: } \mathrm{n}=4 \\
\text { Word problems of numbers: } \mathrm{n}=4\end{array}$ \\
\hline Polynomials & Architecture and civil engineering: $\mathrm{n}=2$ \\
\hline $\begin{array}{l}\text { Quadratic equations, } \\
\text { inequalities, and functions }\end{array}$ & $\begin{array}{l}\text { Mathematics used in mechanics (vertical motion, speed, and } \\
\text { velocity): } \mathrm{n}=6\end{array}$ \\
\hline $\begin{array}{l}\text { Permutation, combination, } \\
\text { and Probability }\end{array}$ & Actuary, statistics and estimation: $\mathrm{n}=7$ \\
\hline
\end{tabular}


Table 1 continued

\begin{tabular}{ll}
\hline Trigonometry & $\begin{array}{l}\text { Architecture, engineering and measuring the length of } \\
\text { objects on earth: } \mathrm{n}=12\end{array}$ \\
\hline Complex numbers & Alternating current and electricity: $\mathrm{n}=5$ \\
\hline Logarithms & $\begin{array}{l}\text { Radioactive decay, bacterial growth, determining age of } \\
\text { fossils: } \mathrm{n}=6 \\
\text { Seismology and Richter scale: } \mathrm{n}=6\end{array}$ \\
\hline Induction and series & $\begin{array}{l}\text { Generalization of the ideas in real life (e.g. behaviors, blood } \\
\text { analysis, solving puzzles): } \mathrm{n}=3 \\
\text { Population growth of animals and growth of animals (e.g. } \\
\text { length of a snake): } \mathrm{n}=3\end{array}$ \\
\hline $\begin{array}{l}\text { Matrix, determinant, } \\
\text { linear equations }\end{array}$ & and \\
\hline Functions & $\begin{array}{l}\text { Pryptography, and computer systems: } \mathrm{n}=8 \\
\text { intervals): } \mathrm{n}=3\end{array}$ \\
\hline Limits and continuity & Limits in real life (e.g. speed, temperature, height): $\mathrm{n}=4$ \\
\hline Differentiation & $\begin{array}{l}\text { Mechanics (rate of change, motion in a straight line) and } \\
\text { engineering (e.g. maximum force): } \mathrm{n}=8\end{array}$ \\
\hline Integration & Finding area and volume of irregular shapes on earth: $\mathrm{n}=10$ \\
\hline
\end{tabular}

\section{Discussion and Conclusions}

In this study, data from teachers and academicians paint a colorful and multifaceted picture of the use of real world connections in high school mathematics and conclusions that can be drawn from data does not provide a clear prescription for curriculum developers, textbook writers and mathematics teachers. Data from the participants reiterate the favorable general perception of the use of real world connections. Participants overwhelmingly agree that real world connections can improve students' motivation, interest and attitudes as well as develop their mathematical reasoning and problem solving skills and conceptual learning. In this way, making real world connections can contribute to improve students' general performance and achievement in mathematics. In fact, this is in line with suggestions from many studies from the related literature; the more students are motivated, the better they perform in mathematics (Gainsburg, 2008; Özdemir \& Üzel, 2011; Reyes, 1984; Sorensen, 2006; Muijs \& Reynolds, 2011).

Real world problems are likely to have multiple solutions, and while finding strategies to solve these problems, students can have a chance to improve their problem-solving and analytical thinking skills. Since the use of connections provides an environment where students develop multiple mathematical approaches to the problems; students deduce and interpret mathematical concepts and can relate them to each other. If handled carefully, this way of teaching may support students becoming inquiring learners (Gainsburg, 2008).

Most participants in this study also thought that real world connections may help to develop awareness of future careers by showing occupational fields in which mathematics is used. To illustrate, while teaching quadratic functions, if an example from actuarial 
science is given to show that the relationship between age and the probability of being involved in a traffic accident is modelled by a quadratic function for a population, students may develop an interest in actuarial science (Sorensen, 2006). In short, the message for curriculum developers and teachers is loud and clear; there is much potential to take advantage of real world connections in high school mathematics.

The majority of the participants thought that there is not a significant disadvantage of using of real world connections in high school mathematics. However, they put forward a cautionary note that the real world context within which the mathematics is presented should not be too complex for the students. There is indeed much indication from the literature that resonates with this suggestion (Boaler 2002; Lubienski, 1998; Muijs \& Reynolds, 2001; Heuvel-Panhuizen, 2003).

One facet of the potential disadvantage however is about the balance between real world connections and the need for symbolic abstraction and generalization while teaching mathematics. About $40 \%$ of the participants thought that using real world connections may make abstract thinking difficult. Although this is not a majority view, a relatively high level of support for this idea requires attention for curriculum developers. In mathematics, teaching in general or abstract terms with deliberate attention to the conditions of use for the mathematical concept may sometimes be more beneficial for learning compared to always situating instruction in context (De Brock et al., 2003). This is an issue that calls for professional judgment for teachers and curriculum developers and warrants further research.

Realistic Mathematics Education calls for starting with experientially real contexts and staying with it throughout instruction (Gravemeijer \& Terwel, 2000). This is often interpreted as starting with a real world problem in a lesson or unit and staying with it up until the assessment phase of the instruction. The data collected in this study points to a cautionary stance and a quest for balance on the part of teachers and academicians. Forty percent of teachers and academicians think that overuse of real world contexts in teaching mathematics may hinder students' ability to reach abstract generalizations and transfer learning to new situations. Further, the majority of participants thought that it may not be suitable to use real world connections for all topics in high school mathematics. Since teaching mathematics in real world contexts typically takes more time than direct abstract instruction, making real world connections may make it difficult to cover the topics of the prescribed national curriculum. Using real world connections at the beginning or at the end of mathematics lessons depends on the nature of the topic according to the participants of this study. Although using the connections throughout the instruction -as called for the Realistic Mathematics Education, was not directly asked to the participants, it can be speculated based on the division of opinion on the place of real world connections in mathematics lessons (at the beginning or at the end) that, situating instruction in real contexts throughout the instruction would probably not be viewed favorably by the participants. Overall, there is evidence in the data of this study to suggest that there is a 
need for care and balance in the use of real world connections in several respects; a level of need for abstract training, time, heavy content of the curriculum and nature and suitability of the topic.

The teachers and academicians were able to offer many reasonable examples of real world connections for topics of high school mathematics. To illustrate, computer software and algorithms are practical examples for teaching logic in real world contexts. Vertical motion, speed and velocity are feasible instances while teaching quadratic equations, inequalities and functions. Alternating current and electricity are examples offered to teach complex numbers in real world context. However, not all examples offered by the participants are practicable. For instance, alternating current and electricity may be a too complex context for many high school students. It is also interesting to note that some examples are not mathematically acceptable. For limits and continuity, limits in real life (such as in high way speed) are offered. A high way 'speed limit' can be an example of the boundary concept in mathematics rather than limit, as values of a function can alternate above and below the actual limit value. It appears curriculum developers, textbook writers, and teachers should carefully select examples by analyzing the mathematical content of the example for each mathematical topic.

It was also interesting that in all but one of the topics, prototypical examples suggested by participants did not reach a level of $50 \%(n=12)$ among the participants. The exception was trigonometry. This may indicate that teachers and teacher educators may need material support about practical examples of real world connections at the high school level. Actually, the participants overwhelmingly agreed that more instructional material in Turkish is needed to support the use of real world connections. This task can be taken up by the Turkish mathematics education community.

Even though there are many benefits of making real world connections in high school mathematics when used with care, teachers and academicians point to at least two important limitations regarding preparedness of teachers and university entrance exams. These limitations concern mathematics teacher educators and the larger mathematics education community in Turkey.

Priority should be given to offer opportunities to prospective teachers in their education while still in university and for in service teachers in professional development programs in the use of real world connections. However, we know from our own experience and the experience of other nations that re-education of in service teachers to use new approaches may not be straightforward. For example, in the Netherlands, Wubbles et al (1997) report that lack of adequately equipped teachers was a problem when a new inquiry-based approach was initiated in school mathematics. At the beginning, changing perceptions of teachers used to teaching in traditional ways was not easy, but it was possible to change teachers in the direction of the new approach when professional development programs were designed and carried out carefully, systematically and sensitively.

Yet, probably the most critical limitation is the heavy presence of the university entrance exam in Turkish classrooms. If only problems that require abstract reasoning 
devoid of any real context are included in this exam -which appear to be the case at present, many teachers and students will see real world connections as a marginal issue that can be ignored. The notion of "what you test is what you get" is a well-known phenomenon in education. The implication for policy makers is that as finding a place in Turkish universities gradually eases up for students, university entrance exams should be changed to reward valuable skills such as being able to relate mathematics to real life, as intended in the statements of the national mathematics curriculum.

\section{Acknowledgments}

The authors wish to thank two anonymous reviewers whose comments contributed significantly to the quality of this article.

\section{References}

Anderson, J. R., Reder, L. M., \& Simon, H. A. (2000). Applications and Misapplications of Cognitive Psychology to Mathematics Education. Texas Educational Review, 1(2), 29-49.

Blum, W. (2002). Applications and modelling in mathematics education. Educational Studies in Mathematics, 14, 149-171.

Boaler, J. (2002). Learning from teaching: Exploring the relationship between reform curriculum and equity. Journal for Research in Mathematics Education, 33(4), 239258.

Cuban, L. (1976). Determinants of curriculum change and stability, 1870-1970. Retrieved from ERIC database. (ED141224)

De Bock, D., Verschaffel, L., Janssens, D., Van Dooren, W., \& Claes, K. (2003). Do realistic contexts and graphical representations always have a beneficial impact on students' performance? Negative evidence from a study on modelling non-linear geometry problems. Learning \& Instruction, 13(4), 441-463.

Department of Education, U. K. (2013). Mathematics programs of study: Key Stage 4 (National Curriculum in England). London: Her Majesty's Stationery Office.

Gainsburg, J. (2008). Real world connections in secondary mathematics teaching. Journal of Mathematics Teacher Education, 11(3), 199-219.

Gravemeijer, K., \& Terwel, J. (2000). Hans Freudenthal: A mathematician on didactics and curriculum theory. Journal of Curriculum Studies, 32(6), 777-796.

Hirsch, C. R. (2007). Perspectives on the design and development of school mathematics curricula. Reston, VA: NCTM.

Joiner, K. D., \& Landreth, G. L. (2005). Play therapy instruction: A model based on objectives developed by the Delphi technique. International Journal of Play Therapy, 14(2), 49-68.

Lubienski, S. (2000). Problem solving as a means toward mathematics for all: A look through a class lens. Journal for Research in Mathematics Education, 31(4), 454, 482. 
Ministry of National Education [MoNE]. (2012). Secondary mathematics curriculum (Grades 9-12) [Ortaögretim matematik (9, 10, 11 ve 12. sinuflar) dersi öğretim programl] Ankara: MoNE

Muijs, D., \& Reynolds, D. (2011). Effective teaching: Evidence and practice (3rd ed.). London, UK: Sage Publications.

National Council of Teachers of Mathematics [NCTM]. (2000). Principles and standards for school mathematics. VA: Reston.

Özdemir, E. ve Üzel, D. (2011). Gerçekçi matematik eğitiminin öğrenci başarısına etkisi ve öğretime yönelik öğrenci görüşleri. Hacettepe University Journal of Education, 40, 332-343.

Patton, J. E. (1997). A life skills approach to mathematics instruction: Preparing students with learning disabilities. Journal of Learning Disabilities, 30(2), 178-187.

Reyes, L. (1984). Affective variables and mathematics education. Elementary School Journal, 84(5), 558.

Saxe, G. (1988). Candy selling and mathematics learning. Educational Researcher, 17(6), 14-21.

Sorensen, V. (2006). Motivating middle school mathematics students. Retrieved from http://digitalcommons.unl.edu/mathmidactionresearch/28/

Van Den Heuvel-Panhuizen, M. (2003). The didactical use of models in realistic mathematics education: An example from a longitudinal trajectory on percentage. Educational Studies in Mathematics, 54(1), 9-35.

Vos, P., \& Kuiper, W. (2005) Trends (1995-2000) in the TIMSS mathematics performance assessment in the Netherlands. Educational Research and Evaluation, 11(2), 141154. Retrieved from http://www.tandfonline.com/doi/abs/10.1080/13803610500110794

Wiersma, W., \& Jurs, S. G. (2009). Research methods in education (9th ed.).Boston, MA: Pearson Education.

Wubbels, T., Korthagen, F., \& Broekman, H. (1997). Preparing teachers for realistic mathematics education. Educational Studies in Mathematics, 32(1), 1-28. 
Appendix A. Open-ended questions of the first round

1. Please give examples with short explanations for the advantages of using real world connections in high school mathematics curricula.

2. Please give examples with short explanations for the disadvantages and limitations of using real world connections in mathematics.

3. Please give one or more example of a real world connection that can be used in the high school mathematics topics listed below.

3a. Logic,

3b. Sets,

3c. Relations, functions, and operations,

3d. Numbers,

3e. Polynomials,

3f. Quadratic equations, inequalities, and functions,

3g. Permutation, combination, and probability,

3h. Trigonometry,

3i. Complex numbers,

3j. Logarithms,

3k. Mathematical induction and sequences,

31. Matrices, determinants, and linear equation systems,

3m. Functions,

3n. Limits and continuity,

3o. Derivatives,

3p. Integration.

4. While teaching a mathematics topic, should mastering the abstract come first with application coming later; or starting with real world connections and then reaching abstract generalizations of the content? Please explain why.

5. Is using real world connections appropriate for all students and classrooms? For example, is it more appropriate to use real world connections with gifted students and easy-to-handle classrooms? Please explain why.

6 . What are some ways to ensure that assessment in the university entrance exams is in line with instruction that makes effective use of real world connections in high schools?

7. Do you believe that high school teachers in Turkey are sufficiently equipped to teach mathematics in a real world context? Please offer suggestions for teacher educators on the use of real world connections to be able to help prepare preservice teachers?

\section{Citation Information}

Karakoç, G., \& Alacac1, C. (2015). Real world connections in high school mathematics curriculum and teaching. Turkish Journal of Computer and Mathematics Education, 6(1), 31-46. 